\title{
Pontine haemorrhage: a clinical analysis of 26 cases
}

\author{
SHOJI MASIYAMA, HIROSHI NIIZUMA, JIRO SUZUKI \\ From the Division of Neurosurgery, Institute of Brain Diseases, Tohoku University School of Medicine, \\ Sendai, Japan
}

SUMMARY Correlation with the size of the haematoma, neurological findings and prognosis was studied in 26 cases of hypertensive pontine haemorrhage, using CT. A good prognosis was found with no or mild disturbance of consciousness, normal pupils, and transverse diameter of the haematoma $20 \mathrm{~mm}$ or less. Most of the patients with poor prognosis became comatose within two hours of onset. Their pupils were dilated bilaterally, pin-point or anisocoric and the transverse diameter of the haematoma was over $20 \mathrm{~mm}$.

The prognosis in cases of pontine haemorrhage has been reported to be extremely poor,' but the widespread use of CT scanning has led to the discovery of small pontine haematomas which previously could not have been diagnosed. In such cases, the prognosis is not always unfavorable. ${ }^{2-14}$ We report the clinical symptoms, CT findings and prognosis of 26 patients with primary pontine haemorrhage.

\section{Materials and methods}

All cases of arteriovenous malformation and cryptic angioma were excluded leaving 26 cases of pontine haemorrhage brought to hospital within 24 hours of onset between July 1978 and April 1982 (table 1). Twenty were male and six were female, with ages ranging between 33 and 68 years (mean 50 years).

Study was made of the symptoms at onset, level of consciousness on admission, pupillary and other cranial nerve findings and $10 \mathrm{~mm}$ thick slice CT findings in relation to the transverse and longitudinal diameters of the haematoma, the number of CT slices in which the haematoma was visible and the presence or absence of ventricular enlargement.

\section{Results}

(a) Clinical symptoms, therapy and prognosis The symptoms at onset were headache and vomiting in 10 patients, vertigo in seven, hemiparesis in six, loss of consciousness in five and unilateral sensory disturbance in two.

Address for reprint requests: Dr S Mashiyama, Division of Neurosurgery, Tohoku University School of Medicine, Institute of Brain Diseases, 2-1 Seirgo-cho, Sendai, Japan 980.

Received 30 October 1984

Accepted 5 December 1984
On admission, consciousness was present in five cases, somnolent to semicomatose in seven cases and comatose in 14 cases. Five of the comatose patients had lost consciousness immediately after onset, eight lost consciousness within two hours and one had lost consciousness four hours from onset. Pupils were dilated bilaterally in six cases, bilaterally pin-point in seven cases, normal in eight cases and anisocoria was seen in five cases. Notable lateral asymmetry of motor functions were seen in nine of the 12 patients who remained conscious.

Conservative therapy was used in all cases except Cases 9,12 and 15, for whom continuous ventricular drainage was instituted to alleviate ventricular dilatation.

Of the 26 cases, 11 were discharged in favorable condition, three were in a vegetative state and 12 died. All five of the patients with normal consciousness on admission recovered. Five of the seven patients who were somnolent to semicomatose on admission were discharged in favorable condition, but one was discharged in a vegetative state and one died of gastrointestinal bleeding. In contrast, only one of the 14 patients who were in coma on admission recovered, two were discharged in a vegetative state and all of the remaining 11 patients died within 23 days of onset (table 2).

All eight patients with normal pupils recovered, whereas only two of the five with anisocoria recovered. Among the seven cases with pin-point pupils, only one recovered and all six of the patients with bilateral pupillary dilation died.

At follow-up study after 6-42 months of the 11 patients who were discharged in good condition, five had returned to virtually normal lives, and six had hemiparesis, ataxia or unilateral sensory distur658 
Table 1 Cases of pontine haemorrhage

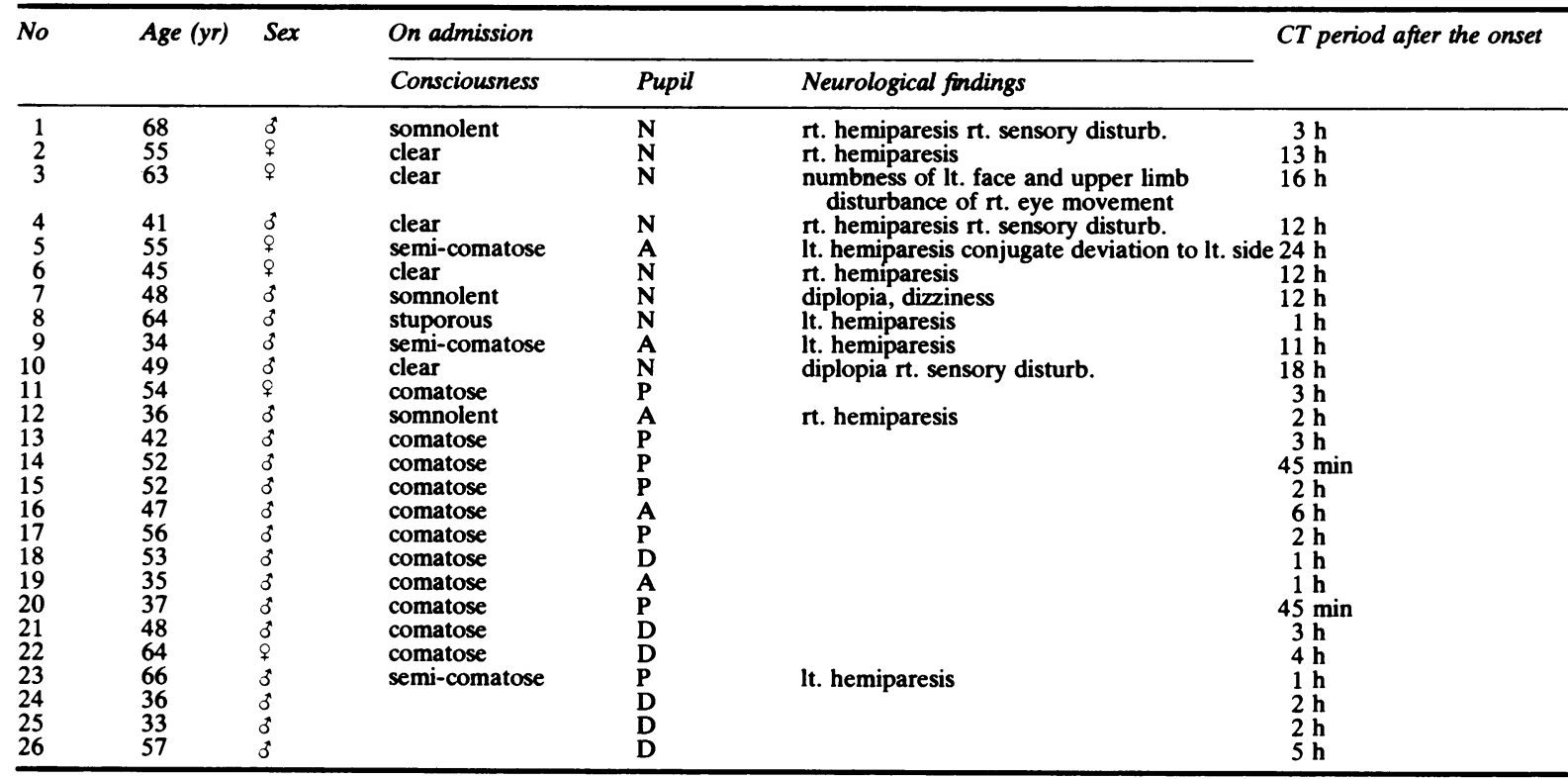

$\mathbf{N}$ : normal; $\mathbf{A}$ : anisocoria; $\mathbf{P}$ : pin point pupil; $\mathbf{D}$ : dilated

* gastrointestinal bleeding; CVD : continuous ventricular drainage.

bances, thus requiring assistance in walking and daily activities. One of these latter patients had severe tremor during motor activity; stereotaxic thalamic VIM destruction was performed and the tremor disappeared.

(b) The relationship between prognosis and the size of the haematoma on admission.

The maximum transverse diameters of the haematomas seen in CT scans ranged from 9 to 33 $\mathrm{mm}$. The patients admitted fully conscious had haematomas with a transverse diameter of $13.8 \pm$ $2.9 \mathrm{~mm}$ (mean $\pm \mathrm{SD}$ ). The diameter was $16.7 \pm 6.4$ $\mathrm{mm}$ in the seven cases in a somnolent-semicomatose state and $25.5 \pm 4.0 \mathrm{~mm}$ among the 14 comatose patients. The difference between these latter groups was statistically significant $(p<0.005)$ (fig 1$)$. Among the 11 cases with favorable outcome, the maximum transverse diameter of the haematoma was $15 \cdot 1 \pm 3.4 \mathrm{~mm}$, whereas among the 15 vegetative cases and deaths, it was $25.2 \pm 5.2 \mathrm{~mm}$, a difference which was again significant $(p<0.005)$. The prognosis of the cases with a maximum transverse diameter of $20 \mathrm{~mm}$ or less was better than those with a diameter of $21 \mathrm{~mm}$ or more (using Fisher's direct test, $\mathrm{p}<0.0002$ ) (fig 2).

The longitudinal diameter of the haematoma was $13.0 \pm 4.3 \mathrm{~mm}$ among those with normal consciousness on admission, $21 \cdot 9 \pm 7 \cdot 1 \mathrm{~mm}$ among those in a somnolent-semicomatose state, and $27.7 \pm 5.1 \mathrm{~mm}$ among the comatose patients. The difference between the two former groups was significant $(p<$ $0 \cdot 05$ ). The relationship between longitudinal diameter and prognosis was as follows: among these with favorable outcome, the longitudinal diameter was $18 \cdot 1 \pm 7 \cdot 2 \mathrm{~mm}$, whereas among those with unfavor-

Table 2 Relationship between level of consciousness on admission and prognosis

\begin{tabular}{lllll}
\hline $\begin{array}{l}\text { Prognosis/level of } \\
\text { consciousness on admission }\end{array}$ & Improved & Vegetative & Dead \\
\hline Clear & 5 & 0 & 0 & 5 \\
Somnolent-semicomatose & 5 & 1 & 1 & 7 \\
Comatose & 1 & 2 & 11 & 14 \\
total & 11 & 3 & 12 & 26 \\
\hline
\end{tabular}

( ${ }^{*}$ gastrointestinal bleeding) 


\begin{tabular}{|c|c|c|c|c|c|c|}
\hline \multicolumn{3}{|l|}{ Haematoma } & Ventricle & Operation & Prognosis & $\begin{array}{l}\text { From onset to death or } \\
\text { present condition }\end{array}$ \\
\hline $\begin{array}{r}9 \\
12 \\
12\end{array}$ & $\begin{array}{r}12 \\
10 \\
9\end{array}$ & $\begin{array}{l}1 \\
1 \\
1\end{array}$ & $\begin{array}{l}\mathbf{N} \\
\mathbf{N} \\
\mathbf{N}\end{array}$ & E & $\begin{array}{l}\text { improved } \\
\text { improved } \\
\text { improved }\end{array}$ & $\left(\begin{array}{l}\text { (good) } \\
\text { good } \\
\text { good) }\end{array}\right.$ \\
\hline $\begin{array}{l}12 \\
12 \\
14 \\
15 \\
15 \\
15 \\
20 \\
21 \\
21 \\
21 \\
21 \\
21 \\
24 \\
24 \\
24 \\
24 \\
27 \\
27 \\
27 \\
30 \\
30 \\
33 \\
33\end{array}$ & $\begin{array}{l}21 \\
12 \\
11 \\
33 \\
24 \\
24 \\
14 \\
20 \\
21 \\
21 \\
24 \\
26 \\
24 \\
24 \\
30 \\
36 \\
27 \\
36 \\
36 \\
27 \\
30 \\
27 \\
27\end{array}$ & $\begin{array}{l}2 \\
1 \\
2 \\
2 \\
2 \\
2 \\
2 \\
1 \\
2 \\
2 \\
2 \\
2 \\
2 \\
2 \\
2 \\
2 \\
3 \\
2 \\
3 \\
3 \\
2 \\
6 \\
2\end{array}$ & $\begin{array}{l}\mathbf{N} \\
\mathbf{D} \\
\mathbf{N} \\
\mathbf{N} \\
\mathbf{N} \\
\mathbf{D} \\
\mathbf{N} \\
\mathbf{N} \\
\mathbf{D} \\
\mathbf{N} \\
\mathbf{D} \\
\mathrm{D} \\
\mathrm{D} \\
\mathrm{D} \\
\mathrm{D} \\
\mathbf{D} \\
\mathrm{D} \\
\mathbf{D} \\
\mathrm{D} \\
\mathbf{N} \\
\mathbf{D} \\
\mathbf{D} \\
\mathbf{D}\end{array}$ & $\begin{array}{l}= \\
= \\
\bar{z} \\
\overline{c V D} \\
\bar{c} \\
\bar{c} \\
\bar{c} \\
= \\
= \\
= \\
= \\
= \\
= \\
=\end{array}$ & $\begin{array}{l}\text { improved } \\
\text { dead } \\
\text { improved } \\
\text { improved } \\
\text { improved } \\
\text { improved } \\
\text { improved } \\
\text { improved } \\
\text { improved } \\
\text { dead } \\
\text { dead } \\
\text { no change } \\
\text { no change } \\
\text { dead } \\
\text { dead } \\
\text { dead } \\
\text { dead } \\
\text { dead } \\
\text { dead } \\
\text { no change } \\
\text { dead } \\
\text { dead } \\
\text { dead }\end{array}$ & $\begin{array}{l}\text { (good) } \\
\text { 12 D } \\
\text { (fair) } \\
\text { (fair) } \\
\text { (good) } \\
\text { (fair) } \\
\text { (fair) } \\
\text { fair) } \\
\text { (fair) } \\
7 \mathrm{H} \\
9 \mathrm{D} \\
\text { (vegetative) } \\
\text { (vegetative) } \\
20 \mathrm{H} \\
5 \mathrm{H} \\
3 \mathrm{D} \\
3 \mathrm{D} \\
2 \mathrm{D} \\
23 \mathrm{D} \\
\text { (vegetative) } \\
2 \mathrm{D} \\
3 \mathrm{D} \\
16 \mathrm{D}\end{array}$ \\
\hline
\end{tabular}

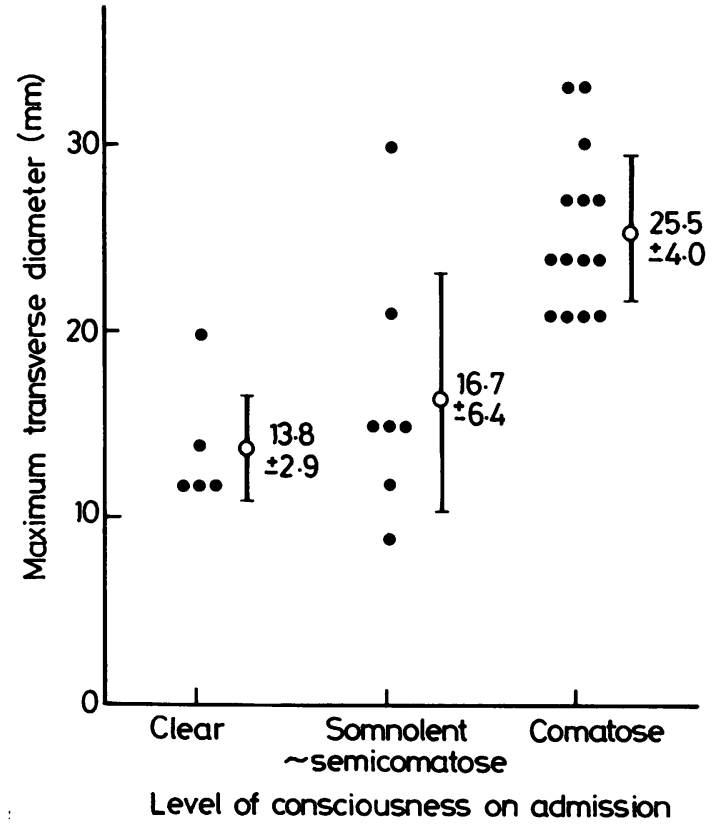

Fig 1 The relationship between the transverse diameter of the haematoma and the level of consciousness on admission. 
Table 3 Relationship between the number of slices in which the haematoma was found and prognosis

\begin{tabular}{lccc}
\hline $\begin{array}{l}\text { Prognosis/number of } \\
\text { slices }\end{array}$ & Improved & Vegetative + dead & Total \\
\hline 1 & 4 & $1^{*}$ & 5 \\
2 & 7 & 10 & 17 \\
3 or more & 0 & 4 & 4 \\
total & 11 & 15 & 26 \\
\hline
\end{tabular}

( ${ }^{*}$ gastrointestinal bleeding)

able outcome, it was $27 \cdot 1 \pm 6 \cdot 1 \mathrm{~mm}$, a difference which was significant $(\mathrm{p}<0.01)$.

It was found that prognosis was favorable in all five of the cases in which the haematoma was visible in one slice, with the sole exception of the one patient who died of gastrointestinal bleeding. In contrast, all four of the patients in which the haematoma was visible in three or more slices died. (table 3).

Ventricular enlargement was seen in 15 of the 26 cases $(57.7 \%)$. The size of the haematoma in those with ventricular enlargement was $24.2 \pm 5.6 \mathrm{~mm}$, whereas it was $16.5 \pm 5.6 \mathrm{~mm}$ among the 11 without ventricular enlargement. The difference between the groups was significant $(p<0 \cdot 005)$.

Two of the three cases in which there was ventricular enlargement and subsequent continuous ventricular drainage had favorable outcomes, and the other became vegetative. Among the 12 in which continuous ventricular drainage was not performed, there were no favorable outcomes, whereas nine of the 12 cases without ventricular enlargement had favorable prognoses.

\section{Discussion}

Among various kinds of intracerebral bleeding, primary pontine haemorrhage is known to have the worst prognosis. Following a sudden onset, there is often early coma with tetraplegia, decerebrate posture, respiratory disturbance, hyperthermia, and pin-point pupils. Prior to the advent of CT scanning, even when it was possible to make a diagnosis of a brainstem lesion, it was frequently not possible to diagnose a pontine lesion. The diagnosis of pontine bleeding usually had to await necropsy. With $\mathrm{CT}$, however, it is possible to discover small haematomas which previously could not have been diagnosed, and it is now known that the prognosis of pontine lesions is not always poor. Mortality due to pontine haemorrhage is reported to be between 30 and $68 \cdot 7 \% .^{513-15}$ Various studies of the correlation between prognosis and haematoma size in CT scans have been made. Ochiai et al "' have reported that patients with high density CT areas which do not exceed $1 / 4$ the cross-section of the mid-pons survived for 30 days or more, whereas the prognosis when the haematoma exceeds $1 / 4$ is extremely poor. Nishitani et al $^{10}$ found (from 21 cases of pontine haemorrhage in which CT scans and necropsy study were possible) that the 15 cases which survived for only short periods had haemorrhage in the entire pons and extending into the fourth ventricle, midbrain and thalamus. In contrast, the six patients who survived for lengthy periods had haemorrhage confined to the pons or present unilaterally. Tanaka et al ${ }^{13}$ classified pontine haemorrhage into (1) massive type, (2) basis tegmentum type, and (3) tegmentum type. They note that the prognosis for the massive type of haemorrhage is poor, but the prognosis for longterm survival and functional recovery of tegmentum type cases is good. The prognosis of basis tegmentum type haemorrhage is midway between the others.

Notable among previous CT studies attempting to measure the size of the pontine haematoma is the study of Tanabe et al. ${ }^{14}$ Measurement of both transverse and longitudinal diameters revealed that prognosis was correlated to transverse diameter. Among survivors, maximum transverse diameter was $31.5 \mathrm{~mm}$ or less, whereas most fatal cases had haematomas exceeding that size. Kuwabara et $a^{5}$ reported that cases with maximum haematoma diameters $20 \mathrm{~mm}$ or less and seen in three CT slices or less of $10 \mathrm{~mm}$ thickness have haematomas confined to the pons with favorable prognoses.

In the present study, we have found that a stronger correlation is found between prognosis and the transverse haematoma diameter than with the longitudinal diameter. The weaker correlation with longitudinal diameter is thought to be due to the following factors. When measuring the longitudinal diameter, it is not always clear whether or not the haematoma has penetrated the fourth ventricle. Consequently, all high density areas must be considered as regions of pontine destruction, despite the fact that it is uncertain whether the high density area is the lesion itself or merely blood in the ventricle. It was found that the prognosis of cases with haematoma of maximum transverse diameter of 20 mm or less often was favorable, whereas it often was poor when the haematoma exceeded $21 \mathrm{~mm}$. We therefore conclude that the upper limit of haematoma size for favorable prognosis is somewhat smaller than the $31.5 \mathrm{~mm}$ suggested by Tanabe et $a l .{ }^{14}$ With regard to the number of slices in which the haematoma was found, the prognosis was favorable when the haematoma was seen in only one slice and poor when seen in three or more. When seen in two slices, the prognosis varied between favorable and 
unfavorable. Ventricular enlargement was frequently seen when the haematoma was large.

In view of these findings, the level of consciousness and prognosis of pontine haemorrhage cases is largely determined by the size of the haematoma at onset, particularly by the transverse diameter. That is, 13 of our 16 cases with haematoma of transverse diameter exceeding $21 \mathrm{~mm}$ were comatose within two hours of onset and subsequent recovery was poor. In contrast, when the transverse diameter was $20 \mathrm{~mm}$ or less, consciousness deteriorated at worst to a simicomatose state following onset and subsequent recovery was good, clearly suggesting two groups with markedly different prognoses. Those in the former group can be identified from clinical signs and symptoms alone, but definitive diagnosis of the latter group requires CT scanning.

Therapy in severe cases which become comatose within two hours of onset is exceedingly difficult. In contrast, if consciousness is clear, somnolent or semicomatose, the prognosis is relatively good and conservative therapy is appropriate. In some patients who are somnolent or semi-comatose, extirpation of the haematoma has been attempted. Koba et al $^{6}$ reported three deaths and two patients capable of returning to domestic life requiring assistance among five operated cases. Such results, however, cannot be said to be superior to conservative therapy and further study of the indications for surgery is required.

\section{References}

' Kanaya H, Yamada T, Koana K, Okudera T. Clinicopathological study of pontine hemorrhage. Brain Nerve 1968;20:49-55.
${ }^{2}$ Brister J, Himdelt B, Nilsson O. Benign brainstem hematoma. Acta Neurol Scand 1979;60:178-82.

${ }^{3}$ Dhopesh VP, Greenberg JO, Cohen MM: Computed tomography in brainstem hemorrhage. Comput Tomogr 1980;4:603-7.

${ }^{4}$ Kase CS, Maulsby GO, Mohr JP. Partial pontine hematoma. Neurology, (Minneap) 1980;30:652-5.

${ }^{5}$ Kuwabara S, Ohta K, Ueda T, et al. Clinical study of 20 cases of primary pontine hemorrhage. Neurol Med Chir (Tokyo) 1982;22:933-42.

- Koba G, Yokoyama T, Kaneko M. Clinical and pathological studies of hypertensive pontine hemorrhage. In: Kitamura K, ed. Proc 6th Conf Surg Treat Strokes (Fukuoka) 1977;6:177-84.

${ }^{7}$ Lavi E, Rothman S, Reches A. Primary pontine hemorrhage with complete recovery. Arch Neurol 1981;38:320-1.

${ }^{8}$ Miki Y, Deguchi H, Hara H, et al. Recovery from pontine hemorrhage. Nissei Hospital Zasshi 1980;8:193-6.

' Nakajima K, Itoh Z, Suzuki K. Mild cases of pontine hemorrhage. Brain Nerve 1979;31:569-76.

${ }^{10}$ Nishitani M, Wada K, Kamata H, et al. Clinical study of primary pontine hemorrhage. Jpn J Stroke 1979; 1:229-31.

"Ochiai C, Sano K, Kobayashi S, et al. Clinical study of pontine hemorrhage with special reference to $C T$ classification and surgical indication. Brain Nerve 1979;31:803-11.

12 Payne HA, Maravilla KR, Levinstone A, et al. Recovery from primary pontine hemorrhage. Ann Neurol 1978;4:557-8.

${ }^{13}$ Tanaka Y, Nishitani M, Ogasawara S, et al. Clinical study of hypertensive pontine hemorrhage. Brain Nerve 1982;34:601-7.

14 Tanabe Y, Kondoh H, Funakoshi T, et al. Clinical study of pontine hemorrhage. Jpn J Stroke 1981;3:162-3.

is Motofuji H, Yoshida Y, Sogabe Y, et al. Brainstem lesion caused by cerebrovascular diseases-clinical symptoms and CT findings. Jpn J Stroke 1980;2:355-63. 